\title{
A Seleção dos Encarregados da Jurisdição: o Sistema Espanhol em Perspectiva Crítica'
}

Claudia Roesler ${ }^{2}$

\section{Considerações iniciais}

O presente artigo versa sobre um tema pouco discutido na bibliografia jurídica e das ciências sociais no Brasil - os mecanismos de seleção dos magistrados - e parte da observação do caso espanhol. O objetivo principal é verificar em detalhes como funciona o mecanismo atual de seleção, o concurso público denominado de "oposición", cujas origens históricas remontam ao século XIX, bem como oferecer ao leitor brasileiro uma visão crítica do sistema.

A bibliografia internacional tem dado destaque, ainda que seja um destaque relativo e recente, a esse tema. Uma explicação acerca do fato pode ser tomada a partir da constatação da visibilidade política e social que o Poder Judiciário assumiu nas últimas décadas, trazendo consigo um debate importante sobre a função judicial e seus limites e provocando uma série de indagações de caráter prático: Quem são os juízes? Como são recrutados? Quais os mecanismos de avaliação e

Este artigo representa parte dos resultados finais de um estudo desenvolvido na Espanha em 2006 com financiamento da CAPES e em colaboração com o Prof. Dr. Manuel Atienza, da Universidade de Alicante. Agradecemos ao Prof. Atienza e ao Prof. Aguiló Regla, que conosco discutiram esse trabalho, bem como a Manuel Miranda Estrampes da Escuela Judicial de Barcelona e a Perfecto Andrés Ibáñez, Magistrado do Tribunal Supremo, por todo o apoio, material bibliográfico e sugestões. O estudo integra, ainda, o projeto de investigação intitulado "Jurisdição, argumentação e políticas Públicas" da Linha de Pesquisa Produção e Aplicação do Direito do Mestrado em Ciência Jurídica da UNIVALI/SC.

2 Doutora em Direito pela Faculdade de Direito da Universidade de São Paulo e Pós-doutora pela Universidade de Alicante, Espanha. Professora dos cursos de Graduação em Direito, Mestrado Acadêmico em Ciência Jurídica e Mestrado Profissionalizante em Gestão de Políticas Públicas da Universidade do Vale do Itajaí - UNIVALI/SC e da graduaçāo em Direito do Complexo de Ensino Superior de Santa Catarina - CESUSC. 
controle de sua atividade jurisdicional? Como medimos a qualidade dos "serviços" prestados pelos órgãos judiciais? ${ }^{3}$

Como resume Guarnieri (2001), a relação entre qualidade da prestação jurisdicional e as modalidades de seleção pode ser vista de pelo menos três importantes ângulos. Em primeiro lugar, as modalidades pelas quais se escolhem os membros do Poder Judiciário revestem-se de uma especial importância para o funcionamento do sistema jurídico e refletem-se na qualidade global da justiça, o que significa dizer que para melhorar a prestaçāo jurisdicional não basta que pensemos em como organizar melhor os tribunais, se não incluímos nessa reflexão a necessária qualificação profissional dos juízes que os compõem.

Em segundo lugar, se pensamos de um ponto de vista macro, o modo pelo qual são selecionados os membros do Poder Judiciário atua diretamente sobre o perfil de juiz que se produzirá e, a partir daí, sobre a concepção do Direito, do seu papel como juiz, da natureza e dos limites da sua função, que terá não apenas o juiz em sua dimensão singular, mas o próprio corpo judicial. ${ }^{+}$

Em terceiro lugar, as modalidades de recrutamento interferem diretamente na independência e imparcialidade dos juízes, as quais condicionam a qualidade da prestação jurisdicional, especialmente em circunstâncias como as atuais, nas quais uma parte considerável da atividade judicial desenvolve-se controlando a constitucionalidade e a legalidade da administração pública e da produção legislativa. Assim, sistemas de recrutamento que privilegiam a capacidade profissional reforçam a independência ao produzir uma maior identificação com a função profissional exercida e diminuem o papel de influências impróprias de caráter externo (GUARNIERI, 2001).

Podem-se conceber, ainda que seja uma generalização, dois modelos básicos de recrutamento dos membros do Poder Judiciário nas sociedades democráticas

Ressaltando as implicaçōes teóricas e práticas de pesquisas sobre essa temática, afirma Di Federico, 2005, p. V: "A research on the functioning of recruitment, professional evaluation, career, and discipline of judges and prosecutors in different countries has both scientific and practical implications. In analyzing and comparing those features in various judicial systems, the values of independence and impartiality are in many ways revealed in their multifaceted aspects. In fact, the higher the actual guarantees of professional qualifications in the various systems, the higher also are the guarantees of independent and impartial behaviour of the judge (insofar as his technical preparation and his deeply rooted professional values make him far less likely to be receptive to improper external influences)."

+ Neste sentido, afirma Guarnieri, 2001, p. 26-27: “En efecto, aunque es verdad que no existe una relación estrecha entre características socioeconómicas, actitudes de los jueces y sus decisiones, los mecanismos de reclutamiento condicionan de todos los modos las características generales del cuerpo judicial, el tipo de juez e en definitiva la concepción del papel de este último que tiende a prevalecer dentro de la magistratura (MURPHY; TANENHAUS, 1972; GIBSON, 1983). Sobre todo, puesto que en los regímenes democráticos los jueces tras ser designados gozan de garantías de independencia cada vez mayores, su comportamiento depende cada vez menos de la influencia del gobierno o de los superiores jerárquicos y cada vez más de la concepción que se tenga del propio papel y en general de los valores que tienden a compartir. Por ello en estos términos se puede decir que las modalidades de reclutamiento de los jueces influyen en sus decisiones." 
ocidentais: o do juiz "profissional", ${ }^{5}$ recrutado dentre membros bem-sucedidos de carreiras jurídicas e detentor de uma experiência profissional que abaliza a sua nomeação ao cargo e legitima o exercício da função jurisdicional, presente nos países vinculados à tradição da common law; ${ }^{6} \mathrm{e}$ o do juiz "funcionário" que, mais característico dos países vinculados à tradição romano-germânica, trabalha com sistemas de recrutamento baseados em concursos públicos e aposta em um aprendizado da função no próprio exercício desta, dentro da organização judicial, pois o perfil geral do juiz recrutado é o de um jovem bacharel em Direito, cuja experiência profissional é pequena ou inexistente (GUARNIERI, 2001).

Se avaliarmos o sistema burocrático, também denominado de modelo do juiz "funcionário", incorporado às estruturas estatais e participante de uma carreira estruturada, os prós e contras resultam bastante significativos. De um lado, uma seleção baseada em provas, escritas ou orais, que avaliem os conhecimentos técnicos deve levar a uma escolha dos mais bem capacitados tecnicamente para a função, bem como evitar ingerências externas de caráter político ou abertamente clientelistas. Por outro, uma sistemática de seleção como os concursos públicos torna difícil avaliar as condições reais de capacidade para o exercício da atividade judicial, pois acaba por privilegiar a resposta a uma gama mais ou menos ampla de questōes, em um momento localizado no tempo, a partir do qual, se o resultado é aceitável, considera-se a pessoa como incluída em uma categoria profissional cujas atribuições são de alta responsabilidade política e social, muitas vezes com a vitaliciedade no cargo e com poucos (ou nenhum) mecanismos efetivos de formação inicial ou continuada.

Como ressalta Guarnieri (2001), vários são os problemas a serem enfrentados pelos sistemas burocráticos de recrutamento. Em primeiro lugar, a dificuldade em implantar-se um mecanismo que permita alcançar os objetivos institucionais da magistratura e que implica em obter um comportamento mais ou menos uniforme de seus membros. Isso se consegue, afirma o autor, por uma combinação, em graus variados, de duas opções: um recrutamento inicial altamente exigente que garanta a qualidade da pessoa que se recruta (normalmente presente no modelo do juiz "profissional") ou uma ênfase no treinamento e na comprovação das qualidades buscadas por meio de uma sistemática de sançōes positivas e negativas capazes de estimular os comportamentos desejados pela organização. A estrutura-

\footnotetext{
5 Para auxiliar a visualizar melhor as implicaçōes do modelo, pode-se utilizar a idade média dos ingressantes na magistratura, a qual se encontra na Inglaterra entre os 50 e os 60 anos e nos Estados Unidos, ao menos para a magistratura federal, mais prestigiada e importante do ponto de vista do sistema judicial, é menor do que na Inglaterra mas consideravelmente mais alta do que nos países da Europa continental. A respeito, vide Pederzoli e Guarnieri, 1999, p. 37-38.

6 A propósito dessa característica, afirma Iñaki Aguirreazkuenaga, 2004, p. 12: "Sin embargo, desde la perspectiva del sistema de nombramiento o elección de los jueces hay una clave que se repite de modo constante en los modelos de corte anglosajón, y es la exigencia de una variada y sólida experiencia práctica a todos quienes vayan a ejercer funciones judiciales."
} 
ção da carreira e dos mecanismos de avaliação para a progressão nela, ${ }^{`}$ bem como as estruturas de formação continuada que se podem vincular a isso, são, portanto, fundamentais nesse contexto. Em segundo lugar, a circunstância de que o modelo suponha um perfil generalista de juiz, capaz de desempenhar muitas funções e de conhecer (e bem) todos os ramos do Direito. ${ }^{8}$ Por fim, mas não por último em grau de importância, a problemática nascida da formação técnico-jurídica altamente legalista que marca os sistemas de ensino do Direito dos países nos quais se utiliza o modelo de juiz "funcionário" e que estão francamente inadequados ao perfil que as Constituições desses mesmos sistemas jurídicos exigem.

O sistema espanhol de seleção dos juízes encaixa-se no modelo de juiz "funcionário" que acima caracterizamos brevemente e tem suas origens no século XIX, sob forte influência do modelo napoleônico. Conta basicamente com uma seleção pública, aberta aos bacharéis em Direito, que se costuma chamar de "oposiciones". Os aprovados nessa fase são então integrados à Escuela Judicial que os preparará, com uma série de atividades práticas e teóricas, para o efetivo exercício da função judicial.

Além de partilharmos com a Espanha a inclusão no sistema de recrutamento denominado acima de "juiz funcionário", a experiência espanhola oferece ao estudioso brasileiro do Poder Judiciário algumas peculiaridades que a tornam um excelente objeto de reflexão na busca por um sistema de seleção e formação adequado à magistratura brasileira, objetivo que vem sendo buscado de modo mais incisivo, por determinação constitucional, desde a EC nº 45/2004.

Dentre essas peculiaridades podemos resumidamente mencionar a semelhança existente entre nosso sistema jurídico, de origem romano-germânica, e o deles, bem como a presença de uma forte cultura jurídica legalista cuja aplicabilidade prática entra em crise com a promulgação de uma constituição dirigente e com grande carga principiológica após a redemocratização do país. Por derradeiro deve-se mencionar também o fato de que há, especialmente se compararmos com o Brasil, uma bibliografia relativamente consolidada que discute a temática e cuja qualidade é bastante significativa.

Para cumprir com o objetivo proposto o artigo é dividido em quatro partes: na primeira se apresenta o desenho normativo da seleção; na segunda se verifica

É de se registrar, neste sentido, a experiência italiana, que aboliu a carreira judicial enquanto um escalonamento de tipo hierárquico-burocrático, num esforço de democratização do Poder Judiciário. Sobre a experiência italiana muito se produziu em termos de análise, mas pode-se consultar, para uma idéia geral de como funciona o sistema, Pederzoli, 2001 e a Di Federico, 2005, p. 127 ss.

8 Neste sentido, afirma Pederzoli, 2001, p. 83: "Por último, en estos contextos, las estructuras organizativas tienen aún la impronta de modelos culturales expresados por la ciencia jurídica - el carácter sistemático y autosuficiente de esta disciplina, la idea de un juez 'omnisciente' que debería ser capaz de abarcar a todas las ramas del Derecho - y que deja todavía vislumbrar una cierta desconfranza respecto a la especialización de las asignaturas no jurídicas. Así el generalismo sigue impregnando no sólo la formación universitaria sino también la práctica y las propias modalidades de asignación a las funciones de los magistrados." 
como os candidatos ao concurso se preparam para ele; na terceira parte se apresenta um balanço crítico da sistemática de seleção.

\section{O sistema de seleção}

O sistema de seleção inicial para o cargo de juez ${ }^{9}$ encontra-se regulado pela Ley Orgánica del Poder Judicial (LOPJ), reformada sucessivamente ${ }^{10}$ e aguardando um decreto regulamentar, e pelas convocatórias que se fazem a cada dois anos para realizar os concursos e que são emitidas pela Comissão de Seleção vinculada ao Consejo General del Poder Judicial.

De acordo com o previsto no art. 305 da LOPJ, a Comissão de Seleção é um órgão permanente do Consejo General, com mandato de quatro anos, cuja composição é a seguinte: um membro do Consejo General del Poder Judicial e um Fiscal de Sala (ou seja, um membro da Fiscalía que esteja no último posto da carreira) que se alternam anualmente na presidência da comissão; um magistrado, um fiscal, o diretor da Escuela Judicial, o diretor do Centro de Estudios Juridicos, um membro do corpo técnico do Consejo General del Poder Judicial e um funcionário do Ministério da Justiça com nível de subdiretor, ambos licenciados em Direito, que atuarão alternadamente como secretários da comissão. Os membros pertencentes à carreira judicial e ao Conselho são indicados pelo próprio Conselho e os fiscales pelo Fiscal General, o funcionário do Ministério da Justiça pelo respectivo Ministério. A referida comissão tem competência para fixar os temas do concurso, o conteúdo dos exercícios e as normas complementares que se fizerem necessárias.

Assim, nossa exposição utilizará como base a última convocatória emitida pela Comissão de Seleção, pertinente ao período de 2005/2007, que se destina a preencher 75 vagas para alunos da Escuela Judicial e 130 do Centro de Estudios Jurídicos. Os concursos são comuns às duas carreiras - juízes e fiscales - e os aprovados optam, segundo a ordem de classificação obtida na oposición, pelo ingresso na carreira que lhes agrada e assim ingressam na escola específica. São reservadas, por disposição expressa da reforma efetuada na LOPJ em 2003, 5\% das vagas aos candidatos que passarem nas provas e apresentarem incapacidades físicas que não sejam incompatíveis com o exercício das funções.

\footnotetext{
9 No sistema espanhol denomina-se "juez" aquele que participa da carreira em suas fases iniciais e reserva-se a expressão magistrado para os juízes que estão em fases mais avançadas da carreira, especialmente na segunda instância. O termo fiscal ou abogado-fiscal, por fim, qualifica os membros do Ministério Público espanhol. A reforma ocorrida na Ley Orgánica del Poder Judicial em 2000 unificou o concurso para as duas carreiras.

10 A Ley Orgánica del Poder Judicial sofreu inúmeras alteraçōes desde que se promulgou a primeira lei orgânica, cujo status corresponde ao das leis complementares no sistema jurídico brasileiro, em 1985, e atualmente encontra-se aguardando uma regulamentação via decreto, pois o último decreto, datado de 1995, perdeu sua aplicabilidade ao ser revogado pela alteraçāo ocorrida na LOPJ em 2003.
} 
Os candidatos devem ser espanhóis, licenciados em Direito, não estarem incursos em nenhuma causa de incapacidade prevista pela lei e não estarem no período de aposentadoria e nem chegar a ela durante o período de realização do concurso e do período de formação inicial. Realizadas as inscrições, a Comissão publica a lista dos que foram considerados aptos a participarem do concurso e os que foram excluídos.

A Comissão nomeia em seguida o Tribunal Calificador, ou seja, o tribunal que procederá de fato à seleção dos candidatos. Este tribunal é composto por: um magistrado do Tribunal Supremo ou de um Tribunal Superior ou um Fiscal de Sala, do Tribunal Supremo ou de Tribunal Superior, que será o presidente; dois magistrados; dois fiscales; um professor catedrático da universidade de disciplina jurídica em que consistam as provas; um Abogado del Estado; um advogado com mais de dez anos de experiência; um secretário judicial de primeira categoria que atuará como secretário (LOPJ, art. 304).

Esse tribunal nomeado pela Comissão de Seleção é denominado de Tribunal 1 e preexiste à realização da primeira etapa, um teste com questões de múltipla escolha. Após a realização da primeira etapa do concurso e dependendo do número de aprovados, serão nomeados tantos tribunais quantos forem necessários para proceder às duas etapas subseqüentes, ambas orais. Esses tribunais, com a mesma composição, estarão coordenados pelo Tribunal 1, embora sejam independentes para a avaliação dos candidatos.

A primeira parte do concurso, anunciada com dez dias úteis de antecedência e realizada em várias cidades ao mesmo tempo se for conveniente, consiste em responder a cem perguntas com quatro alternativas cada uma, das quais apenas uma é correta, em um tempo de duas horas e trinta minutos. Das cem perguntas, dez correspondem a Teoria Geral do Direito e Direito Constitucional, 40 a Direito Civil, 30 a Direito Penal, 20 de Direito Processual, 13 de Processual Civil e 7 de Processual Penal. A pontuação da prova será de zero a cem pontos e cada questão certa valerá um ponto, cada questão errada será descontada em 0,33 e cada questão deixada em branco não pontuará.

A nota de corte não é fixada de antemão, ou seja, o tribunal decidirá, posteriormente à realização da prova e sua correção, qual a nota mínima para continuar participando do concurso. Essa medida tem a intenção de evitar que o tribunal fixe uma nota de corte muito alta e acabe, nas etapas seguintes e diante do resultado delas, ficando sem candidatos a examinar.

A segunda fase será anunciada com dez dias úteis de antecedência e a relação com os nomes dos candidatos que serão examinados em cada sessão diária será divulgada com pelo menos doze horas de antecedência. Os que não comparecerem e não apresentarem motivos justificados estão eliminados.

Os tribunais realizam a prova ouvindo os candidatos que expõem oralmente os temas sorteados dentre os constantes como anexo à convocatória, trezentos e sessenta temas distribuídos entre todas as áreas do conhecimento jurídico. Os cinco temas são distribuídos da seguinte forma: um tema de Teoria Geral do Di- 
reito e de Direito Constitucional, dois temas de Direito Civil e dois temas de Direito Penal. Os candidatos têm em torno de quinze minutos para preparar sua exposição, fazendo um esquema sem o uso de qualquer material de consulta e um período de setenta e cinco minutos para expor os cinco temas, sendo que não devem destinar mais de vinte minutos a nenhum deles, o que significa que cada tema deverá ser desenvolvido oralmente pelo candidato em um período de mais ou menos quinze minutos. As seçōes sāo públicas.

Se os membros do tribunal entenderem, por unanimidade, que o candidato não está expondo adequadamente o tema que lhe foi destinado, podem interrompê-lo e encerrar a prova, fazendo constar em ata. Em relação àqueles que terminam a exposição dos cinco temas, após o encerramento o tribunal decide, por maioria, se o candidato foi ou não aprovado e faz constar em ata. Quando se considera aprovado, então o tribunal atribui uma nota traduzida em uma soma de pontos. Cada tema exposto recebe uma nota de 0 a 5 de cada um dos membros, inclusive daquele ou daqueles que tenha considerado o candidato reprovado. A nota final resulta da soma de todas as notas, excluindo-se a máxima e a mínima, e dividindo-se pelo número de notas somadas. Ao final de cada dia de prova são divulgados os nomes dos candidatos examinados no dia e a pontuação obtida por cada um, sem que se faça constar da lista os que foram convidados a retirar-se ou reprovados.

Da terceira fase participam apenas os que foram aprovados na segunda e ela deve ser realizada no mínimo um mês após o encerramento da outra e anunciada com quinze dias de antecedência.

A terceira fase transcorre do mesmo modo, modificando-se apenas os temas sobre os quais a exposição terá de ser realizada: dois temas de Direito Processual Civil, um tema de Direito Processual Penal, um tema de Direito Mercantil, um tema de Direito Administrativo ou do Trabalho.

A classificação dos candidatos faz-se pela soma das notas obtidas na segunda e na terceira fase e é encaminhada pelo Tribunal 1 à Comissão de Seleção para divulgação. Em caso de empate entre candidatos, prevalece aquele de maior idade. O Tribunal não pode aprovar mais candidatos do que as vagas do concurso e, caso um dos tribunais tenha aprovado menos candidatos do que as vagas que lhe foram atribuídas, essas vagas serão preenchidas por candidatos aprovados por outros tribunais. A compatibilização das notas obtidas e a confecção da lista final dos aprovados ficam a cargo do Tribunal 1.

Os aprovados optam, segundo a sua ordem de classificação, pelo ingresso na carreira judicial ou de fiscal e adquirem, a partir daí, o status de funcionários en prácticas, ou seja, passam a receber remuneração (LOPJ, art. 306).

\section{Como se prepara um candidato à seleção}

Os candidatos à seleção por oposición libre precisam ser capazes, como vimos, de recitar os cinco temas em um tempo limitado e fazê-lo de memória. Essa cir- 
cunstância faz com que a preparação para as provas consista basicamente em desenvolver dois conjuntos de habilidades: memorização do conteúdo e capacidade de síntese e habilidade para expressar-se de modo correto e confiante sobre os temas no tempo desejado.

A inclusão recente do exame escrito tipo teste agregou a esse quadro a necessidade de o candidato preparar-se para escolher, dentre as quatro alternativas propostas como respostas a cada questão, a única correta. As questões e suas respostas são geralmente baseadas em conhecimentos de direito positivo estrito, ou seja, no texto legal ou constitucional, e exigem também uma memorização adequada dos conteúdos. A sua introdução na seleção, portanto, não alterou substancialmente o modo de preparação dos candidatos.

A fórmula usual de preparação, tão tradicional quanto a existência das oposiciones, é de que o candidato interessado em preparar-se para a seleção, após concluído o curso de graduação em Direito que tem uma duração média de cinco anos, procure um juiz, magistrado ou fiscal para orientá-lo e servir como seu preparador.

A função do preparador consiste, portanto, em estabelecer um cronograma de estudo do temário da seleção, constante, como vimos, de trezentos e sessenta temas, controlar a adequada memorização e corrigir a forma como o opositor, como se costumam designar os candidatos, recita os temas.

Assim, desde o princípio da preparação, o preparador cobrará do opositor o seguimento de uma pauta de estudo rígida, composta de uma média de oito a dez horas diárias de estudo, com um dia de folga por semana, sem direito a férias. O período de preparação oscila entre um mínimo de dois anos e um máximo de quatro anos. Em quatro anos a maioria dos candidatos que persistiram e conseguiram desenvolver as habilidades necessárias são aprovados. ${ }^{11}$ Como o sistema de preparação é informal, não há números disponíveis para avaliar a quantidade de candidatos que sucumbem pelo caminho e acabam por desistir.

Durante a preparação as férias e os longos afastamentos da rotina de estudos são evitados porque implicam em um período no qual os conhecimentos a serem memorizados não serão repassados e se perderá algo do esforço já realizado. Trata-se, como se pode perceber, de um esforço de longo tempo e de grande persistência para o candidato.

Os preparadores recebem um pagamento mensal que oscila segundo o renome do preparador e a realidade da cidade na qual desempenha seu trabalho, mas que poderíamos situar entre 120 e 300 euros. Como são parte de um sistema completamente informal, esses valores não costumam ser declarados como renda recebida, nem há qualquer lista pública ou mecanismo de controle sobre a ativi-

\footnotetext{
Pesquisas realizadas pela Escuela Judicial com os candidatos que foram aprovados no concurso e passam a freqüentá-la apontam para um média de 3 anos e 11 meses. A pesquisa foi realizada com os ingressantes na escola no período de 1999 a 2005.
} 
dade. Um preparador pode ter tantos opositores quantos julgar conveniente. ${ }^{12}$ Os opositores chegam aos preparadores por indicaçōes informais obtidas com outros participantes do sistema jurídico: professores na universidade, colegas de curso, advogados, juízes e fiscales, amigos etc. A avaliação do trabalho do preparador e seus resultados também se faz nessa espécie de rede de informação informal.

O trabalho é individualizado e normalmente consiste em uma ou duas reuniões semanais de pelo menos uma hora de duração. Nessa reunião se faz uma checagem dos pontos que devem ser recitados e o preparador ouve e controla, mediante o uso de um cronômetro, o tempo que o candidato utilizou para a exposição, corrigindo também o uso da linguagem e a adequação ao conteúdo desejado. Em síntese: se o candidato consegue recitar o conteúdo adequado no tempo previsto de quinze minutos. Eventualmente faz-se alguma pequena discussão ou esclarecimento de dúvida, menção às inovações legislativas ou debates doutrinários, mas o centro da preparação não consiste nisso, já que o candidato não será questionado pelo tribunal e deverá limitar-se a expor o tema. Mais do que capacidade de reflexão, as habilidades fundamentais são a síntese e a memorização.

O material didático para o estudo consiste em conjuntos de textos desenvolvidos por algumas editoras com base no temário das convocatórias. Como as mudanças ocorrem, mas não chegam a alterar profundamente a maior parte dos temas pedidos entre uma convocatória e outra, de fato o que o candidato faz é memorizar os conteúdos a partir de um conjunto de pontos estabelecidos nesses textos-guia. Um dos materiais que examinamos, editado pela Editorial Carperi, e que é o mais utilizado, consta de treze volumes. Programado como assinaturas anuais ou mensais e recebido pelo correio, o material é atualizado conforme a necessidade, ou seja, segundo alteraçōes de temário ou reformas legislativas. $\mathrm{O}$ custo básico desse material está em torno de 600 euros.

No material didático mencionado o temário estabelecido na convocatória é desdobrado em um texto com as informações necessárias, remissões ao texto da lei etc., em um espaço que muitas vezes não passa das quinze páginas. O número, longe de ser cabalístico, atende ao pragmático propósito de auxiliar o opositor a aprender a recitá-lo à razão de uma página por minuto, totalizando os quinze minutos requeridos com o conteúdo todo exposto. $\mathrm{O}$ teor do texto, ademais, tenta permanecer o máximo possível nas informações neutras, ou seja, que não provoquem as eventuais discordâncias de membros do tribunal que podem seguir essa ou aquela perspectiva doutrinária e por isso recusar o candidato. O preparador também intervém nesse sentido, corrigindo o candidato na exposição dos temas

\footnotetext{
12 A informalidade que cerca o sistema de preparaçāo torna difícil avaliar qual a repercussāo econômica para os preparadores e se este é ou nāo o objetivo principal dos que se dedicam à atividade. A justificativa que se ouve, no entanto, é que prestar serviços como preparador nāo é algo que se faça por motivos estritamente financeiros, mas sim para continuar atualizado ou auxiliar as pessoas que desejam ingressar nas carreiras jurídicas. Aparentemente, portanto, a dimensão de retribuição financeira aparece quase como "vergonhosa" na relação que se estabelece entre preparador e opositor.
} 
para dar o tom mais neutro e com maior conteúdo possível, mas sem entrar em polêmicas doutrinárias que possam afastá-lo da percepção de algum dos membros do tribunal.

Quanto ao seu conteúdo pode-se dizer que é uma sistematização dos conteúdos vistos na universidade, com um privilégio bastante grande ao texto legal. Hernández García e Saiz Arnaiz (2003) em uma análise geral do temário apontam a sua baixa adaptação ao caráter constitucionalista do ordenamento jurídico espanhol após a Constituição de 1978 e sua perfeita identificação com o temário de trinta ou de cinqüenta anos atrás, preparado para uma realidade na qual o Direito Civil era o direito por excelência e espelhado em um sistema jurídico pensado para uma sociedade cuja economia girava em torno do setor primário, cuja composição cultural, étnica e religiosa era homogênea e que se inseria em um contexto de grande isolamento internacional. O Direito civil responde por um quarto dos tópicos inseridos, com a agravante de dele constarem institutos jurídicos muito pouco relevantes para os problemas jurídicos atuais enquanto outros institutos que aparecem de maneira massiva no cotidiano dos tribunais recebem o mesmo ou menor espaço. Do ponto de vista do Direito Penal, dizem os autores, o mesmo ocorre.

Mas a maior crítica que se pode fazer ao temário, seguindo Hernández García e Saiz Arnaiz (2003), é a pouca visibilidade que dá ao Direito Comunitário e ao Direito Constitucional que aparecem misturados com alguns poucos tópicos de Teoria Geral do Direito e que constituem, como afirmam os autores, uma confusa miscelânea que dá a impressão ao leitor de que essa parte serviu para que se colocassem juntos uma profusão de temas que não se sabia exatamente onde colocar. Um exemplo que os autores não tinham em mente, mas que confirma a sua opinião, é a inclusão das questões surgidas pela legislação de combate à violência de gênero como último tema dessa parte, ocorrida em 2004.

Os preparadores costumam utilizar métodos mais ou menos parecidos de preparação dos candidatos sob seus cuidados, alguns dos quais têm inclusive uma denominação conhecida. Um dos sistemas que se utilizam é denominado de "sistema de repasses contínuos" e consiste em dividir os dias do mês e da semana em um conjunto de temas que o candidato deve aprender e outros que deve repassar, de modo que ele esteja continuamente ampliando a base de conhecimentos e tornando aos pontos que já memorizou para fixá-los e não esquecê-los. O outro sistema conhecido chama-se de "sistema de repasse por voltas" e consiste em aprender todo o temário de uma determinada área, como Direito Civil, por exemplo, e ao final retomar todos os pontos vistos.

Em geral os opositores não podem trabalhar no período em que se estão preparando, ou, se o fazem, encontram grandes dificuldades para conciliar trabalho e preparação, dada a quantidade de horas que se necessitam, como vimos acima. Não havia até recentemente nenhum tipo de financiamento público para a preparação, de modo que o candidato deveria arcar integralmente com os custos de sua 
manutenção e da preparação. Isso implicava, como é óbvio, uma limitação bastante grande aos candidatos que, mesmo desejando preparar-se, advêm de famílias cuja renda não é o bastante para mantê-los durante quatro anos sem trabalhar e arcar com os gastos aí implicados.

Em 2006 o governo espanhol instituiu um sistema de financiamento público que provê bolsas de estudos ou financiamentos a baixo custo para os candidatos que se preparam para o concurso. A dotação orçamentária para o período $2006 / 2007$ foi fixada em 270.000 euros anuais, que correspondem a 75 bolsas e a mais 45.000 euros para auxílios em forma de financiamento. As bolsas são de 3.000 euros anuais e nos financiamentos os candidatos podem obter até 10.000 euros anuais. ${ }^{13}$ Os valores concedidos, como se vê, nāo chegam a representar uma significativa alteração no quadro que descrevemos, embora representem um esforço de integraçāo de candidatos de baixa renda aos que acedem à carreira. A justificativa para tal medida encontra-se precisamente na constatação de que a magistratura espanhola em seu conjunto representa muito pouco o espectro social, como bem lembra Manuel Miranda Estrampes (2006), na medida em que apenas os setores de classe média e média-alta conseguem chegar aos postos estatais.

Além disso, o esforço continuado e com as características que apontamos desenvolve em muitos candidatos uma série de distúrbios psicológicos, passageiros ou não. Conforme aponta Jimenez Asensio (2001), a ansiedade, a angústia e os quadros de desequilíbrio emocional não são raros nos opositores. A pressão sofrida para adequar-se ao padrão proposto e a ameaça de um fracasso que significa ter desperdiçado um número razoável de anos não jogam um papel pequeno nesse quadro.

Por fim, deve-se apontar também a circunstância de que os moldes em que a preparação se dá acarretam para muitos candidatos uma vida monástica ${ }^{14} \mathrm{em}$ múltiplos sentidos. São muitos os relatos e é um lugar-comum a idéia de que os candidatos devem deixar para ter relações amorosas mais duradouras ou estáveis e casar-se somente após a aprovação nas oposiciones. O cultivo de relações de amizade e de integração com o meio social em que vivem também não é estimulado e nos parece dificultado pelas características do processo, cuja tônica é a solidāo do indivíduo que luta contra si mesmo para memorizar os temas e adquirir autoconfiança suficiente para recitá-los de modo adequado perante o tribunal. A idade

\footnotetext{
13 De acordo com Orden Jus/2468/2006 de 25.7.2006 e Resolución 1.8.2006 do Centro de Estúdios Constitucionales. Ambos os documentos estão disponíveis em: <www.poder.judicial.es>.

14 Um defensor do atual sistema usa expressamente a expressāo noviciado, que corresponde ao período de preparação dos monges para o ingresso no monastério. Nesse sentido, De Miguel Garcilopez, 1973, p. 13: "Por otra parte - y sobre esto podría testificar fehacientemente la experiencia de los preparadores - el mero hecho de someterse a la preparación en serio, durante años, de las oposiciones de ingreso, con los sacrificios de todo orden inherente a este duro noviciado, para concurrir, como final, a una rigurosa y leal competición, de resultados nunca predecibles con certeza, presupone, por lo general, en este 'Cuerpo de opositores' [...] vocación, rectitud y temple nada endebles que, por ello, no parecen reclamar demasiados desvelos moralizadores o mentalizadores, prodigables en las horas disponibles en la Escuela [...]".
} 
média dos aprovados, segundo dados coletados pela Escuela Judicial com os jueces en practicas, é de 28 anos e $68,47 \%$ confirmam não ter tido nenhuma experiência profissional. Produz-se, assim, o perfil de um indivíduo pouco integrado na sociedade em que vive, já que as experiências de vida que terá nos quatro anos de preparação o levarão mais à solidão que à integração e ao afastamento do que ao partilhar do senso comum da comunidade em que se insere. ${ }^{15}$

\section{Críticas e propostas de alteração do sistema}

A análise que fizemos demonstrou que a observação inicial de que o sistema de seleção da magistratura espanhola inseria-se no modelo do juiz funcionário, também chamado de modelo burocrático, encontra perfeito respaldo na realidade.

O traço marcante do sistema, em perfeita consonância com o modelo burocrático de recrutamento, é a firme presença da oposición libre como mecanismo de seleção. Se esse é um denominador comum dos sistemas que partilham o modelo, no caso espanhol ele vem acrescido do caráter memorístico. O modelo de provas orais é, assim, a marca saliente do sistema espanhol e, se recebe críticas desde praticamente a sua criação em 1870 , também resiste bravamente aos intuitos de mudança e mesmo de discussão. A assimilação histórica que parece ter ocorrido é entre a objetividade (e conseqüentemente a ausência de práticas clientelistas) e o sistema de provas orais, meramente "cantadas". De um modo mais ou menos difuso, permeia a prática da oposición a idéia de que, se o tribunal fosse liberado para realizar questionamentos, poderia haver o favorecimento ou a perseguição aos candidatos avaliados. A idéia de um monólogo com conteúdo praticamente predeterminado não é, assim, gratuita, mas se ampara na perspectiva de que se todos "cantarem" os temas de modo semelhante, serāo escolhidos os melhores, sem favorecimentos indevidos.

A ausência de qualquer experiência prática anterior ao ingresso na magistratura, confirmada pelos números levantados pela Escuela Judicial, evidencia que o perfil do juiz que ingressa na carreira produzido pelo modelo de seleção é o de um jovem inexperiente, consubstanciando assim outro dos traços marcantes do modelo burocrático.

Se o modelo espanhol atende bem aos traços do modelo burocrático, também sofre, como seria de se prever, das dificuldades apontadas por Guarnieri (2001): implantação de mecanismos que permitam produzir, de modo mais ou menos generalizado, comportamentos adequados em termos de eficiência e de responsabilidade social e política se o recrutamento ocorre mediante concursos

\footnotetext{
15 Andrés Ibañez (2000, p. 11) traz, a propósito desse tema, uma interessante citaçāo que resume bem o que apontávamos: “encerrado en casa sin salir de casa más que a misa los domingos y demás fiestas de guardia, hasta nueva orden', que es como Ríos Sarmiento veía la preparación de las oposiciones en Recuerdos de un magistrado español".
} 
que privilegiam a resposta a uma gama dada de questões técnicas; o perfil generalista; a formação legalista em dissonância com o perfil constitucional do juiz contemporâneo.

Quanto ao primeiro ponto a análise que fizemos nos mostra que a solução encontrada no sistema espanhol foi a introdução da formação inicial na Escuela Judicial como mecanismo de socialização dos novos juízes, de aprimoramento de suas qualidades técnicas e de produção de uma certa "cultura" institucional que garanta os objetivos da organização judiciária. A formação continuada e os mecanismos de progresso na carreira podem também funcionar para a consecução desses mesmos objetivos, como aponta Guarnieri. A realidade do sistema espanhol, no entanto, parece não estar adaptada ou não ter sido pensada para isso, tendo em vista que a formação continuada é meramente optativa e a progressão na carreira se faz, em larga medida, por critérios puros de antiguidade. O critério da antiguidade, matizado ou não com a avaliaçāo da experiência, conta com o expressivo apoio dos magistrados.

No que tange ao segundo ponto, o perfil de um juiz generalista que tem de conhecer todas as múltiplas e multifacetadas áreas do Direito é claramente a buscada pela oposición libre com um temário de 360 temas. O custo social e pessoal da preparação é a face negativa mais visível desse fenômeno. Sua face menos aparente, mas igualmente importante, pode ser encontrada, em nossa opinião, no alto percentual de magistrados que consideram fundamental a formação continuada, que deveria ser tornada obrigatória segundo a opinião que expressam em quase unanimidade. ${ }^{16}$ Certamente as dificuldades de lidar com um corpo de normas que não cessa de expandir-se estão por detrás dessa opinião. Por outra parte a especialização é incentivada para a ocupação de vários postos na organização judiciária espanhola, como uma atenuação desse perfil generalista.

Por fim, as dificuldades marcadas por Guarnieri quanto à adaptação do modelo, dada a prevalência de uma cultura legalista, ao perfil constitucional exigido para o juiz, podem ser encontradas em evidência no sistema espanhol. Neste sentido a Constituição de 1978 deu ao juiz um conjunto de atribuiçōes que o colocam em posição institucional de guardião dos direitos fundamentais e da própria Constituição enquanto projeto político de futuro para a sociedade espanhola. Todavia, como também vimos, o temário da oposición mal contempla os temas de Direito Constitucional, exemplificando bem uma visão legalista do Direito, e a formação inicial recebida pelo juez en prácticas ao ingressar na Escuela Judicial tenta minimizar essa ausência incluindo um bloco temático exclusivamente dedicado ao Direito Constitucional e Comunitário. Cabe pensar, no entanto, se essa medida paliativa é suficiente.

16 O Consejo General del Poder Judicial faz pesquisas de opinião internas, como os juizes e magistrados, e externas, com a sociedade, em intervalos regulares. Esses dados podem ser consultados em Informe sobre la encuesta a todos los jueces y magistrados en servicio activo. Madrid: Consejo General del Poder Judicial, 2006. Disponível em: <www.poderjudicial.es>, bem como em TOHARIA CORTÉS, 2005. 
Sem dúvida, se poderia pensar que as provas orais memorísticas cumprem um papel importante, pois obrigam o opositor, como vimos, a memorizar as informaçōes necessárias para localizar as normas jurídicas no sistema e a desenvolver a segurança necessária para enfrentar o tribunal avaliador. A pergunta chave, no entanto, é se essa concepção de que o Direito constitui um conjunto de normas, topograficamente localizadas e de sentido literal, é a concepção adequada para um operador jurídico que maneja o sistema jurídico contemporâneo. As críticas realizadas ao formalismo e ao positivismo normativista nas últimas décadas põem pelo menos uma sombra de dúvida em uma resposta prontamente afirmativa à questão. De outra parte e em sentido muito mais prosaico, a memorização encontra um limite claro: a quantidade de alterações legislativas e de normas que compõem o ordenamento jurídico em contínua expansão. Por fim, as decantadas habilidade e segurança para enfrentar o tribunal avaliador, dado o caráter eminentemente oral da prova, são, sem dúvida, importantes, mas seriam melhor avaliadas se o candidato fosse submetido ao questionamento do tribunal e não apenas se limitasse a "cantar" os temas sorteados.

A outra pergunta que se poderia fazer é se a concepção do Direito que se encontra por detrás do caráter memorístico pode ser atenuada com o período de formação inicial e, caso a resposta seja afirmativa, se vale a pena, em termos sociais e pessoais, investir tanto esforço em memorização e em uma maneira de conceber o fenômeno jurídico que logo em seguida será relativizada, se não claramente questionada. Em termos mais objetivos: não seria mais adequado, tanto para os indivíduos que se preparam, quanto para o sistema como um todo, se as provas de seleção fossem pensadas de modo a estimular o estudo do Direito sem os ranços legalistas e normativistas e em seguida complementar isso na formação inicial?

Como bem lembra Perfecto Andrés Ibañez (2006), é certo que um Poder Judiciário não se faz apenas de elementos estruturais e organizativos. Uma certa cultura da jurisdição se faz presente, complementando e explicando como se devem realizar as atividades da prática jurídica. Nesse sentido, o modelo napoleônico de juiz burocrático, do qual é tão tributário o sistema espanhol, não se faz apenas da regulação jurídica da sua organização, mas da cultura da qual provém e para a qual é ou não funcional. Reformar as instituições significa, em certa medida difusa e indireta, pensar em como se muda uma cultura institucional.

Se seguirmos essa direção podemos pensar que o modelo de seleção revela em praticamente todos os seus traços concretos uma perfeita compatibilidade com a produção de um juiz adequado a um modelo de Direito e de função jurisdicional legalista e conservadora. Para permanecer na terminologia que utilizamos acima seguindo Andrés Ibañez (2006), uma cultura da jurisdição que não privilegia a justificação da decisão judicial, que vê o juiz como um ser à parte e que deve manter-se assim, com um traço autoritário que se mostra de múltiplas formas na sua atuação prática e com uma concepção de seu papel como a de um aplicador da letra da lei que expressa a sua vontade em uma linguagem hermética.

Parece pertinente pensar, neste sentido, que a oposición libre em sua caracterização memorística, seus preparadores e seus opositores de vida quase monástica, 
joga um papel não depreciável na produção dessa cultura. Os meses de formação inicial na Escuela Judicial talvez não sejam suficientes para contrariar esses traços, que, ademais, têm um lastro na cultura jurídica. É oportuno perguntar-se, por exemplo, se o tipo de preparação, derivado do tipo de prova que se faz para o concurso, não traz consigo uma cultura que não favorece a independência pessoal do futuro juiz, pois o obriga, durante um período considerável de tempo, a preparar-se para "não pensar" e repetir. Se a relação preparador/opositor, tão típica do sistema, não traz consigo uma socialização profissional para o futuro juiz na qual predomina a relação de subordinação com traços autoritários. Se, por fim, o isolamento a que se submete o candidato não implicará em um certo distanciamento da própria sociedade em que vive e atuará, como juiz.

A insistência em desmerecer, debilitar ou relativizar o papel da formação inicial, em comparação com o da oposición, pode ser tomada como um indício nessa direção. As posições conservadoras dentro da magistratura espanhola não só vêem com grande desconfiança as tentativas de dar maior peso ao período na Escuela Judicial ou torná-lo francamente eliminatório, como duvidam de sua capacidade de induzir uma cultura institucional e uma ética profissional adequadas. ${ }^{17}$ No máximo admitem que as provas da oposición poderiam ser revisadas para atenuar o caráter excessivamente memorístico e se deveria ter mais cuidado na hora de escolher os membros que compōem os tribunais avaliadores.

A impressão geral do debate sobre modificaçōes no sistema de seleção, que praticamente inexiste como questão que mereça a atenção da comunidade jurídica de modo expressivo, é a de que se trabalha com uma assimilação entre "mudar o sistema" e "eliminar a oposición", como se não houvesse possibilidade de reforma e tudo se resumisse a um jogo de soma zero. A assimilação, normalmente produzida pelas opiniōes conservadoras, aposta em uma radicalização das alternativas e impede que o debate recaia sobre as medidas de correção interessantes e importantes que podem ser tomadas para eliminar as deficiências e ir criando, mesmo que lentamente, uma cultura institucional mais adequada ao perfil de juiz que exige um sistema jurídico como o espanhol.

Conforme Manuel Miranda Estrampes (2006), as posições que se desenham quando um debate desse gênero se produz podem ser agrupadas em dois grandes setores: a linha continuísta que propõe pequenas reformas no temário ou nas características concretas das provas do processo seletivo, mas que insiste no sistema de provas orais como o único capaz de garantir a objetividade; a linha reformista, que pretende modificaçōes mais amplas que adaptem o sistema tanto aos pressupostos do sistema judicial espanhol contemporâneo, quanto que produzam uma mudança no perfil burocrático e elitista que a magistratura tem, em razão mesmo do modelo de seleção adotado. Uma terceira posição seria, como lembra o autor,

\footnotetext{
17 Neste sentido e de modo claro e veemente, De Miguel Garcilopez, 1973, p. 9-10: "En pocas palabras, si hubiera que optar necesariamente - aunque no hay por qué hacerlo - entre la supresión de la Escuela y la de las oposiciones, no es dudoso que nunca deberían ser estas las sacrificadas. En el dilema, más valdría suprimir la Escuela que suprimir la oposición."
} 
uma linha de ruptura que propusesse a eliminação da oposición e sua substituição por mecanismos de recrutamento mais afeitos ao sistema do juiz profissional anglo-saxão. Não há, no entanto, nenhuma posição reconhecida e tornada pública nessa direção.

Se, por fim, alguma conclusão adicional se poderia extrair, essa é a de que um debate teórico sobre o modelo de juiz adequado aos sistemas jurídicos contemporâneos é um objeto importante e necessário. Aprofundar-nos nele e debater que características e que comportamentos deveriam ser buscados, poderia nos ajudar sobremaneira a ter mais clareza sobre as reformas a serem feitas nos sistemas herdados da tradição legalista e burocrática com a qual convivemos.

\section{Referências bibliográficas}

AGUIRREAZKUENAGA, Iñaki. Modelos comparados de organización judicial y régimen de selección o elección de jueces y magistrados. Poder Judicial, $\mathrm{n}^{0} 75$, p. 11-56, 2004.

ANDRÉS IBAÑEZ, Perfecto. El “velo" de la justicia. Claves de Razón Práctica, nº 102, p. 4-11, mayo 2000.

. Cultura(s) de la jurisdicción. Revista do Ministério Público, ano 27, $\mathrm{n}^{\circ} 105$, p. 7-15, jan./mar. 2006 .

CONSEJO GENERAL DEL PODER JUDICIAL. Informe sobre la encuesta a todos los jueces y magistrados en servicio activo. Madrid: Consejo General del Poder Judicial, 2006. Disponível em: <www.poderjudicial.es $>$.

DE MIGUEL GARCILOPEZ, Adolfo. Selección y formación judicial: reflexiones de actualidad. Madrid: s/e. 1973.

DI FEDERICO, Giuseppe. Preface. In DI FEDERICO, Giuseppe (Coord.). Recruitment, professional evaluation and career of judges and prosecutors in Europe. Bologna: Editrice lo Scarabeo, 2005. p. V-IX.

. Recruitment, professional evaluation, career and discipline of judges and prosecutors in Italy. In: DI FEDERICO, Giuseppe (Coord.). Recruitment, professional evaluation and career of judges and prosecutors in Europe. Bologna: Editrice lo Scarabeo, 2005. p. 127-158.

ESPAÑA. Ley Orgánica 6/1985, de 1 de julio, del Poder Judicial. Disponível em: <www. poderjudicial.es/consejogeneral/índicedocumental>. Acesso em: $1^{\circ}$ mar. 2006.

. Ley Orgánica 16/1994, de 8 de noviembre, por la que se reforma la Ley Orgánica 6/1985, de $1^{\circ}$ de julio, del Poder Judicial. Disponível em: <www.poderjudicial.es/consejogeneral/índicedocumental >. Acesso em: $1^{\circ}$ mar. 2006. 
ESPAÑA. Ley Orgánica 9/2000, de 22 de diciembre, sobre medidas urgentes para la agilización de la Administración de Justicia, por la que se modifica la Ley Orgánica 6/1985, de $1^{\circ}$ de julio, del Poder Judicial. Disponível em: <www.poderjudicial.es/consejogene-

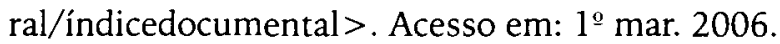

. Ley Orgánica 19/2003, de 23 de diciembre, de modificación de la Ley Orgánica 6/1985, de $1^{\circ}$ de julio, del Poder Judicial. Disponivel em: <www.poderjudicial.es/consejogeneral/índicedocumental >. Acesso em: $1^{\circ}$ mar. 2006.

. Reglamento numero 1/1995, de 7 de junio, de la Carrera Judicial. Disponível em: <www.poderjudicial.es/consejogeneral/índicedocumental>. Acesso em: 20 mar. 2006.

. Orden Jus/2468/2006, de 25.7.2006. Disponível em: <www.poderjudicial. es/consejogeneral/índicedocumental >. Acesso em: 2 mar. 2007.

. Resolución 1/08/2006 del Centro de Estudios Constitucionales. Disponível em: $<w w w . p o d e r j u d i c i a l . e s / c o n s e j o g e n e r a l / i ́ n d i c e d o c u m e n t a l>$. Acesso em: 2 mar. 2007.

GUARNIERI, Carlo. El acceso a la magistratura: problemas teóricos y análisis comparado. In JIMÉNEZ ASENSIO, Rafael (Org.). In: El acceso a la función judicial: estudio comparado. Madrid: Consejo General del Poder Judicial, 2001. p. 20-39.

HERNÁNDEZ GARCÍA, J.; SAIZ ARNAIZ, A. La selección y formación inicial de los jueces en España: algunas reflexiones críticas para un debate necesario (aunque inexistente). Actualidade Jurídica Arazandi, Madrid, p. 1-7, marzo 2003.

JIMÉNEZ ASENSIO, Rafael. El acceso a la judicatura en España: evolución histórica, situación actual y propuestas de cambio. In: JIMÉNEZ ASENSIO, Rafael (Org.). El acceso a la función judicial: estudio comparado. Madrid: Consejo General del Poder Judicial, 2001. p. 117-249.

MIRANDA ESTRAMPES, Manuel. El sistema de selección y la formación inicial de fiscales. Ponencia presentada en el Curso El Fiscal ante los nuevos retos: El Fiscal instructor. Reforma del Estatuto Orgánico y sistemas de selección y formación; organizado por la Unión Progresista de Fiscales, CEJ, Madrid, 2-4 oct. 2006.

PEDERZOLI, Patrícia. El sistema italiano de selección de jueces: situación y perspectivas de futuro. In: JIMÉNEZ ASENSIO, Rafael (Org.). In: El acceso a la función judicial: estudio comparado. Madrid: Consejo General del Poder Judicial, 2001, p. 81-114.

; GUARNIERI, Carlo. Los jueces y la política. Traducción de Miguel Ángel Ruiz de Azua. Madrid: Taurus, 1999.

TOHARIA CORTÉS, José Juan. La imagen externa e interna de la justicia. In: TOHARIA CORTÉS, José Juan; GARCÍA DE LA CRUZ HERRERO, Juan José. La justicia ante el espejo: 25 años de estudios de opinión del CGPJ. Madrid: Consejo General del Poder Judicial, 2005. 